ㅅ.. 4591 October 26, 1957

descriptions of apparatus and accessories (such as sampling devices and integrators), especially in connexion with commercial gas chromatographic equipment. As it is proposed to publish the full proceedings of the symposium in the near future, this report will be confined to those developments described at the symposium which seem to be of more immediate and general interest.

In the opening lecture, M. J. E. Golay (PerkinElmer) described his theoretical studies on the performance of a simplified gas-liquid chromatographic system, in which the liquid phase was held on the walls of a fine capillary. In such a system there should be no contribution to plate height (or peak spreading) from a channelling or 'eddy' term. Golay showed how the usefulness of such columns could be measured in terms of a 'performance index' (Nature, 180, 435 ; 1957), in which the drop in pressure across the column and the time for analysis are included as the price paid for sharpness of the peak. An account was given of some experimental work which had been undertaken to test the theory. The results were also of great practical interest, in that sharp separations (equivalent to about 10,000 plates) had been obtained with simple columns. Furthermore, it was found possible to run capillary columns extremely rapidly.

The behaviour of solid support materials was discussed by T. Johns (Beckman Instruments), and E. A. Hinkle and S. E. J. Johnsen (Monsanto Chemical Company, Texas City) showed how peak areas (using a thermistor detector) could be converted to molar concentrations by the use of vapour densities as correcting factors. C. S. G. Phillips (Oxford) deseribed work using metal salts (in particular, zinc and copper stearates and nickel oleate) as column liquids. $\mathrm{H}_{\theta}$ pointed out that the strong forces between metal atoms and the ligand (solute) molecules made possible new types of separation. Changes in relative retention times up to several thousandfold in favourable cases (as, for example, with amines) could be obtained by this method. Such changes were also of value for the characterization of solute substances. He showed how the results with the metal salts columns could be related to studies of complex ion formation in aqueous solution, and how gas chromatography might thus be used for studying complexing equilibria. The use of gas chromatography in kinetic studies of the isomerization of geometrical isomers, the thermal decomposition of acetylene and the thermal decomposition of light hydrocarbons was discussed by L. F. Hatch (University of Texas), and in the study of the hydrogenation products of benzene by R. E. Rippere (General Electric Co.).

H. R. Felton (du Pont, Wilmington, Delaware) described a novel and compact high-temperature gas chromatography unit, in which the detector was a thermal conductivity cell using model-acroplane glow. plugs. Sensitivity and response data for the unit were given from $40^{\circ} \mathrm{C}$. to $550^{\circ} \mathrm{C}$, and its use was illustrated by analyses of the fluoroesters of camphoric acid (boiling points $320^{\circ}$ C. $-460^{\circ}$ C.), the $\alpha$ - and $\beta-N$-phenylnaphthylamines and the toluene isocyanates. The factors affecting the selection of thermistors for use in katharometers formed the subject of a useful study by P. H. Stirling and C. B. Cowan (Canadian Industries, MeMasterville, Quebec), who stressed the importance of matching thermistors for resistance, resistance change with temperature and for dissipation constant. A copper oxide com. bustor as a means for increasing detector response was discussed by S. Norem (Perkin-Elmer).

One session and an invited lecture by B. O. Ayers (Phillips Petroleum) were devoted to the use of gas chromatographic instrumentation for continuous automatic analysis. Two commercial instruments (Perkin-Elmer and Leeds-Northrup) were described in some detail in the contributed papers. Ayers pointed out that a number of analysers were now available commercially, and that these instruments compared most favourably with other types of automatic analysers, especially in the wealth of data which they make available at a relatively low cost for the instrument. $\mathrm{He}$ described the testing of the Perkin-Elmer instrument on typical plant problems.

In a stimulating and entertaining after-dinner speech, A. J. P. Martin described his early work on separation techniques, in association with R. L. M. Synge and later with A. T. James, which led up to the discovery of gas-liquid chromatography. $\mathrm{He}$ commented on present trends in the field, the influence of gas chromatography on other techniques and its many possible applications. He concluded with some suggestions for the future of the method, including the development of the completely automatic analyst.

C. S. G. Phillirs

\section{MACROMOLECULAR CHEMISTRY}

\section{INTERNATIONAL SYMPOSIUM}

$T$ HE Macromolecular Commission of the International Union of Pure and Applied Chemistry broke entirely new ground this year by holding the tenth Symposium, on "Macromolecular Chemistry", in Prague. The success of this penetration into Central Europe and, for the Western countries, behind the Iron Curtain, is reflected in the record number of active participants housed in the Hotel International in the outskirts of the city in which the meetings, except for the opening session, were also held. This procedure lent an air of informality to the proceedings and, by keeping all participants in intimate contact with one another, fostered a feeling of friendly co-operation throughout the week.

No praise is high enough for the diligence, care and thoroughness with which the Organizing Committee, under the leadership of Prof. O. Wichterle, had laid its plans. Almost all the 200 papers and lectures were available in preprint form (Russian and Czech manuscripts were translated into English). To overcome the language difficulty still further, a very efficient cabinet translation service was in continuous session during the presentation of lectures and papers. All delegates were supplied with 10-channel transistor receiver head-sets which carried the translation service in Czech, Russian, French, English and German. This very fine piece of organization was much appreciated by all who took part and removed most of the strain of following complicated argument in a foreign tongue.

The matter of the Symposium was divided into two large sections dealing with $(a)$ physics and physical chemistry of macromolecules and $(b)$ polyreactions. These broad units were subdivided into smaller sections each dealing with a group of related problems in the field. The proceedings were initiated with a lecture by Prof. Paul Doty on "Biological Polymers". 
This took the form of an exemplary review of the field to which the lecturer has made so many outstanding contributions. In the second Symposium lecture, Prof. H. Mark (Brooklyn) related with his usual enthusiasm and vigour the progress in polymer research and technology in the past year. His close contacts with the industrial and academic sides in the United States always make his lectures of very great interest and importance to European audiences.

Each of the sectional meetings was introduced by a lecture on a specific problem on the field. These lectures were later open to discussion, a feature which was novel to the Symposium but produced much of interest and importance. Both lectures and discussion are to be published in Chemické Listy and in Collection of Czechoslovak Chemical Communications. Prof. A. Peterlin (Ljubljana) introduced the group discussing statisties, thermodynamies and kinetics, with a lecture on the excluded-volume effect on the properties of macromolecules in solution. The properties of macromolecules in solution have long been the province of the Strasbourg school, so that it was fitting that the two sessions of this section were addressed respectively by Prof. $\mathrm{H}$. Benoit, on the problems posed by polydispersity and molecular anisotropy in light scattering, and by Dr. R. Cerf, on the flow birefringence of macromolecular solutions. Prof. A. V. Kargin (Moscow), who dealt with structure and phase-state of polymers, discussed in detail the results of electron and X-ray diffraction and electron microscopy studies of 'Terylene', polytrifluorochloroethylene polyethylene, nylon and caprolactam polymers. Prof. F. A. Müller (Hamburg) in the same section concentrated on the deformation behaviour of polymers, especially under great deformation.

The biggest of the smaller sections dealt with the subject of radical addition polymerization, to which four sessions were allotted. In the first of these Prof. S. S. Medvedev (Moscow) gave a critical review of the present ideas of the mechanism of emulsion poly. merization, a topic on which his own views tend to be at variance with the generally accepted theory of Smith and Ewart. Prof. G. V. Schulz (Mainz) described, in detail and with numerous illustrations, the use of polymerization as a test reaction for investigating the kinetics of radical reactions. In recent years the use of high-energy radiation, particularly gamma-radiation, has been exhaustively investigated as a method of initiating polymerization. It was particularly fitting that Prof. M. Magat (Paris), a pioneer in this field, should open the session dealing with this type of work. The problem of the kinetics of high-conversion reactions was treated by Prof. G. M. Burnett (Aberdeen), who reviewed past work and suggested an empirical approach which appeared to fit the experimental data. The seotion dealing with ionic mechanisms was addressed by Dr. D. C. Pepper (Dublin), who analysed in critical detail the various steps in the polymerization process and directed attention to the importance of ionic intermediaries in the polymerization of cyclic imines and oxides. Under the heading of other mechanisms of polymerization Prof. K. Zeigler (Mullheim) and Prof. F. Danusso (Milan), respectively, spoke on the use of organometallic compounds in the production of high polymers and on the kinetics of stereospecific polymerization. These papers occasioned much discussion, thereby underlining the wisdom of choosing specifically this field for the next Symposium, to be held at Nottingham in 1958.
The contribution of the host country was made by Prof. O. Wichterle (Prague), in a discussion of the polymerization of caprolactam which included valuable remarks on likely future trends. Prof. R. Simha (New York) tackled the extremely difficult task of attempting a unified hypothesis to explain the great divergences encountered in the pyrolysis of macromolecules. He approached the problem along the lines he has already successfully exploited, and was able by extension of previous methods to put forward convincing conceptions of the mechanism of the reaction. Interaction of polymeric molecules with organic reagents has for long been neglected but, with the rise of the importance of achieving modifications in the shape of graft and block copolymers, this field has now become more widely recognized. Under this heading Prof. W. Kern (Mainz) and Prof. G. Smets (Louvain) contributed interesting and valuable reviews of the current situation. Somewhat strangely in the context of so much discussion of synthetic polymers, the reactions of natural macromolecules such as proteins, nucleic acids and polysaccharides were considered. This section was introduced by Prof. H. Morawetz (New York), who concentrated on some specific effects encountered in polyelectrolyte solutions. The high density of charge along the macromolecule is of great moment in elucidating many of the effects of complexing with counter ions and the like. The extension of such observations from the synthetic to natural polyelectrolytes is likely to be very important. A new section in the symposium was devoted to the inorganic high polymers. The lecturer in this section, Prof. E. Thilo (Berlin), considered in particular the phosphates and silicates. Indeed, most of the section contributions tended to be directed towards these compounds.

Within the compass of a brief review such as this it is not possible to consider, even in passing, the many contributions to the proceedings, nor is it feasible to attempt an objective selection of the more important papers. Altogether some 180 papers were presented, and it is indicative of current lines of investigation to consider these under group headings. The largest groups were those dealing with solutions (34 contributors) and with radical polymerization ( 30 contributors). Properties of gels, melts and solids, and condensation polymerization (including ring monomers), each claimed 24, and natural large molecules, including proteins, nucleic acids and polysaccharides, had 29 contributors. The remaining groups obviously had few contributors, but in common with the more popular sections the standard of the contributions themselves and also of the ensuing discussion was high.

On a national level the distribution of papers is equally interesting. Contrary to expectation, perhaps, the leading nation was Germany (taking East and West Germany together) with 40 contributions, followed by the U.S.S.R. (31) ; France (28) ; Czechoslovakia (25); the United States (17) and Great Britain (16). At the same time the number of papers submitted does not reflect the actual attendance at the Symposium since, for example, the 150 Russians present formed the biggest single group. They were led by Prof. N. V. Semenov, who contributed some interesting observations in discussion.

Outside the conference halls the hospitality of the hosts left nothing to be desired. After the lengthy sessions of the day, entertainment in the evenings was lavish and spectacular, with a deliberate 
flavour of national pride. Alternative entertainment was normally provided, also showing the culture of the country. The high-lights of the week were probably the performance of Dvorak's "Rusalka" in the National Theatre and the traditional Symposium dinner in the Wallenstein Palace.

In retrospect one can sum up the Symposium as being one of the most successful yet held and certainly the best organized. The standard which was set is one which will be found difficult to equal, but it is hoped that something approaching this technical perfection will be reached in other countries, both west and east of the Iron Curtain, in future international symposia.

\section{THE LIBRARY ASSOCIATION}

\section{ANNUAL CONFERENCE}

$I^{\mathrm{s}}$

$\mathrm{N}$ his presidential address to the Library AssociaI tion on September 17 on the theme of "Knowledge and Education", Dr. J. Bronowski said that a civilized society must preserve what its best minds discover, but preservation alone does not make it an educated or even a cultured society. Moreover, an educated society could exist only when knowledge is not merely stored but is also shared, and it was the invention of printing that mado the book an instrument of education. Dr. Bronowski drew on his own experience to illustrate the role that libraries can take in education and above all in self-education, but in science the public libraries have scarcely played that part at all : if they are to do so, they must have the books to enable them to make the language of science familiar to those who are not professional scientists. Besides the classics of literature, we need many more new classies of science--books like those of Sherrington, Eddington and Schrödinger, which looked at new discoveries in a personal way and spoke to the non-scientist through their personal tone and philosophy. He urged the publication of the old and new classics of science in a single series, which he believed would be widely bought and read and would make the language of science familiar to a new generation, showing them the concepts of science for what they are, classical creations which rank among the permanent monuments to the human imagination. He did not think that the printed book was the last instrument of education we would discover, but he was sure that the printed book and the public library would remain the most powerful means for selfeducation.

Dr. Bronowski's address found echoes in several of the addresses which followed. Mr. A. Shaw Wright's review of the thirty years work of the County Libraries Section of the Library Association, in referring to the work of the regional bureaux, to the "Readers' Guides", to the international exchanges of assistants and the help of the Carnegie United Kingd om Trust, indicated also the way in which the county libraries contributed to this work of self-education. It was implicit also in the discussion of the problems of the school library which Mr. E. Blishen introduced under the title "The Reluctant Reader", and it was sounded explicitly by Mr. J. C. Harrison in his "Retrospect and Forecast of Education for Librarianship and Professional Status". Admittedly controversial on some points, Mr. Harrison mado a strong plea for well-educated and trained librarians if the public library is to be an effective instrument of education, and he claimed that at present it offered neither the status nor the remuneration which could attract or hold a sufficient number of those possessing the ability and knowledge required.

Dr. T. A. Margerison took up more specifically Dr. Bronowski's point in discussing the interpretation of science in an address to the reference and special libraries section on September 19. Dr. Margerison asserted that the average layman's ignorance of science was a danger to democracy, and stressed the need for more effective science teaching in the schools, for more writing for the layman by scientists of repute, and for more effective advice to librarians on the choice of scientific books. Mr. B. S. Page in reviewing university library development was concerned with a particular aspect, but his paper is of special interest to the seientist as such. Recalling the assertion of the University Grants Committee in its report of 1921 that an adequate library is not only the basis of all teaching and study but also an essential condition of research, Mr. Page discussed the implications for the university library of the post-war expansion of the universities. The two-fold function of the university library, of supporting both the teaching of the undergraduates and the creative work in scholarship or science of the postgraduate students and the university staff, was not at all easy to balance. Mr. Page emphasized the importance of the library representing to all, and not least to undergraduates, the unity and not the fragmentation of knowledge. The whole question of training the student in the use of the library required more study, and Mr. Page referred to the investigation into the adequacy of present library techniques to the needs of scholarship initiated by the Ford Foundation, and to the pilot survey which the Nuffield Foundation was conducting at Leeds in the use of books in a university library. Stressing the importance of the initiative of the library in connexion with general education, Mr. Page suggested that the university library should include a centre of disinterested reading, looking and listening, and that the right kind of help and the right atmosphere were what the student needed. On the expenditure side, Mr. Page said little. $\mathrm{He}$ pointed out that according to the University Grants Committee's returns for 1955-56, fifteen universities and university colleges spent on books and bindings a total of $£ 214,586$, or about the amount spent by Harvard University alone, the total for England, including Oxford and Cambridge, being $£ 487,786$, but he did not attempt to analyse expenditure or holdings in relation to expansion.

Of the remaining papers, Dr. C. W. J. Higson's review of the libraries of the university institutes of education should be mentioned.

\section{STRIVING FOR RIGOUR IN GREEK SCIENCE}

$\mathbf{N}$ an address delivered at Dublin to Section A (Mathematics) of the British Association, entitled "The Striving for Rigour in Greek Science", Prof. C. Lanczos compared the standards of mathematical rigour set by the Greeks with the stand urds of to-day, and examined their claims to be regarded as complete in terms of the general Greek philosophical back- 